\title{
Commentary: Decoding across sensory modalities reveals common supramodal signatures of conscious perception
}

\author{
Talis Bachmann* \\ Laboratory of Cognitive Neuroscience, School of Law, University of Tartu, Tallinn, Estonia
}

Keywords: neural correlates of consciousness (NCC), consciousness states, contents of consciousness, perception, intermodal perception, cortex, thalamus

\section{A Commentary on}

Decoding across sensory modalities reveals common supramodal signatures of conscious perception

by Sanchez, G., Hartmann, T., Fuscà, M., Demarchi, G., and Weisz, N. (2020). Proc. Natl. Acad. Sci. U.S.A. 117, 7437-7446. doi: 10.1073/pnas.1912584117

\section{OPEN ACCESS}

Edited by:

Marta Olivetti Belardinelli,

Sapienza University of Rome, Italy

Reviewed by:

Stefano Lasaponara,

Santa Lucia Foundation (IRCCS), Italy

*Correspondence:

Talis Bachmann

talis.bachmann@ut.ee

Specialty section:

This article was submitted to

Cognitive Neuroscience,

a section of the journal

Frontiers in Human Neuroscience

Received: 18 April 2020

Accepted: 30 April 2020

Published: 11 June 2020

Citation:

Bachmann T (2020) Commentary: Decoding across sensory modalities reveals common supramodal

signatures of conscious perception.

Front. Hum. Neurosci. 14:195

doi: 10.3389/fnhum.2020.00195
Research on neural signatures of consciousness can be divided between studies of the state of consciousness (Barttfeld et al., 2015; Demertzi et al., 2019) and contents of consciousness (Schurger et al., 2015; Webb et al., 2016), with relatively litte overlap between these two traditions (however, see Aru et al., 2019). Hardly anyone would question that state of consciousness is mediated by panmodal or intermodal mechanisms. On the other hand, signatures of the contents of consciousness have been examined typically by unimodal experimental setups, leaving open the question of whether the mechanisms of contents of consciousness are universal (i.e., panmodal/intermodal) or specific to each sensory modality such as visual, auditory, somatosensory, etc. An important step forward was taken by Sanchez et al. (2020), who revealed supramodal patterns of magnetoencephalography (MEG) signatures of contentful conscious perception, with high measures of decoding success. How did they do this?

In each modality, in the detection paradigm, individually calibrated near-threshold stimuli were presented for $50 \mathrm{~ms}$. Participants had to report the presence or absence of the stimulus (with shamand high-intensity catch trials used in addition to the stimulus presentation trials to control for various artifacts). Brain activity recorded in trials where stimulus was detected was compared with activity from trials where the stimulus was not detected. (Multivariate pattern analysis of MEG signals combined with a searchlight method was used for optimal decodability. Differences in source-level event-related fields between conscious vs. not conscious trials provided the signatures of conscious experience). Decoding analysis in the poststimulus epoch between sensory modalities revealed spatiotemporal activity patterns predicting conscious experience of the stimulus. These activity patterns, extracted also in the no-report experimental conditions, featured activity in primary sensory regions not directly relevant to the task; common signatures of conscious access to contents across sensory modalities were thereby demonstrated. Importantly, intermodal correlates of conscious access emerged relatively late poststimulus (e.g., $>200 \mathrm{~ms}$ ).

The authors (Sanchez et al., 2020) interpret their results in terms of multisensory integration and top-down broadcasting of neural representations. In other words, they seem to assume that specific informational content of different modalities interacts in a way that produces intermodal signatures of conscious perception. However, the method used by Sanchez et al. (2020) does not allow to know 
the sources of these generalized signatures of conscious access unfolding after $200 \mathrm{~ms}$. The top-down broadcast may be either strictly cortical (perhaps mediated by intermodal synchronization; e.g., Friese et al., 2016), originating from frontal systems or thalamo-cortical (or cortico-thalamo-cortical), with afferents from the so-called non-specific thalamic and/or brain stem neurons and propagating in a phasic mode all over the cortex (especially targeting the layer-1 dendrites of the infragranular pyramidal neurons) (Bachmann and Hudetz, 2014; Phillips et al., 2018; Aru et al., 2019). In this case there is no broadcast of the contents to be intermodally integrated, but just a nonspecific, temporally delayed modulation universally directed at the visual, auditory, and somatosensory cortical areas.

Presumably, future research will be able to specify whether the late modally generalized activity as a signature of conscious contentful perception would be strictly cortically generated or originates from subcortical neural units not specified for transmission of sensory contents as the classical relay nuclei

\section{REFERENCES}

Aru, J., Suzuki, M., Rutiku, R., Larkum, M. E., and Bachmann, T. (2019). Coupling the state and contents of consciousness. Front. Syst. Neurosci. 13:43. doi: 10.3389/fnsys.2019.00043

Bachmann, T. (2011). Attention as a process of selection, perception as a process of representation, and phenomenal experience as the resulting process of perception being modulated by a dedicated consciousness mechanism. Front. Psychol. 2:387. doi: 10.3389/fpsyg.2011.00387

Bachmann, T., and Hudetz, A. G. (2014). It is time to combine the two main traditions in the research on the neural correlates of consciousness: $\mathrm{C}=\mathrm{L} \times$ D. Front. Psychol. 5:940. doi: 10.3389/fpsyg.2014.00940

Barttfeld, P., Uhrig, L., Sitt, J. D., Sigman, M., Jarraya, B., and Dehaene, S. (2015). Signature of consciousness in the dynamics of resting-state brain activity. Proc. Natl. Acad. Sci. U.S.A. 112, 887-892. doi: 10.1073/pnas.1418031112

Demertzi, A., Tagliazucchi, E., Dehaene, S., Deco, G., Barttfeld, P., Raimondo, F., et al. (2019). Human consciousness is supported by dynamic complex patterns of brain signal coordination. Sci. Adv. 5:eaat7603. doi: 10.1126/sciadv.aat7603

Friese, U., Daume, J., Göschl, F., König, P., Wang, P., and Engel, A. K. (2016). Oscillatory brain activity during multisensory attention reflects activation, disinhibition, and cognitive control. Sci. Rep. 6:32775. doi: 10.1038/srep32775

Phillips, W. A., Bachmann, T., and Storm, J. F. (2018). Apical function in neocortical pyramidal cells: a common pathway by which general anesthetics can affect mental state. Front. Neural Circuits 12:50. doi: 10.3389/fncir.2018.00050 are (e.g., lateral geniculate). Of course, as MEG sensitivity to deep subcortical neural sources is quite less than that for the cortical units, some animal research with subcortically implanted electrodes or optogenetic devices would be commendable (e.g., Suzuki and Larkum, 2020). Whether the source of widespread modulation might be in the locus coeruleus for launching the noradrenergic boost (Phillips et al., 2018) or some other modulators might be involved (Bachmann and Hudetz, 2014) remains an open question. In one way or another, the approaches arguing and showing that besides the states of consciousness also contents of consciousness have their panmodal neural signatures (Bachmann, 2011; Sanchez et al., 2020) must be taken seriously, as they may change our general views on how the brain "makes" consciousness.

\section{AUTHOR CONTRIBUTIONS}

TB designed the research and wrote the paper.

Sanchez, G., Hartmann, T., Fuscà, M., Demarchi, G., and Weisz, N. (2020). Decoding across sensory modalities reveals common supramodal signatures of conscious perception. Proc. Natl. Acad. Sci. U.S.A. 117, 7437-7446. doi: 10.1073/pnas.1912584117

Schurger, A., Sarigiannidis, I., Naccache, L., Sitt, J. D., and Dehaene, S. (2015). Cortical activity is more stable when sensory stimuli are consciously perceived. Proc. Natl Acad. Sci. U.S.A. 112, E2083-E2092. doi: 10.1073/pnas.14187 30112

Suzuki, M., and Larkum, M. E. (2020). General anesthesia decouples cortical pyramidal neurons. Cell 180, 666-676. doi: 10.1016/j.cell.2020. 01.024

Webb, T. W., Igelström, K. M., Schurger, A., and Graziano, M. S. (2016). Cortical networks involved in visual awareness independent of visual attention. Proc. Natl. Acad. Sci. U.S.A. 113, 13923-13928. doi: 10.1073/pnas.1611505113

Conflict of Interest: The author declares that the research was conducted in the absence of any commercial or financial relationships that could be construed as a potential conflict of interest.

Copyright (c) 2020 Bachmann. This is an open-access article distributed under the terms of the Creative Commons Attribution License (CC BY). The use, distribution or reproduction in other forums is permitted, provided the original author(s) and the copyright owner(s) are credited and that the original publication in this journal is cited, in accordance with accepted academic practice. No use, distribution or reproduction is permitted which does not comply with these terms. 